\title{
Gestão da qualidade da formação dos professores na perspetiva dos estudantes
}

\author{
Lionilda de Sá Nogueira*, José Brito Pacheco** \\ *Universidade de Cabo Verde, **Universidade do Minho
}

\begin{abstract}
Resumo
A procura da qualidade de ensino é importante uma vez que a escola é responsável pela formação dos cidadãos participativos conscientes e responsáveis.

Este trabalho teve como objetivo auscultar os estudantes da formação inicial de professores sobre as suas perceções relativas à qualidade de ensino oferecida na Universidade Pública de Cabo-Verde. A metodologia adotada consistiu no método quantitativo aonde se realizou a revisão bibliográfica e aplicação de inquéritos a estudantes do $1^{\circ} \mathrm{e}$ $4^{\circ}$ ano dos cursos de Ciências da Educação e do ramo ensino.

Palabras clave: formação de profesores, qualidade, ensino e gestão,
\end{abstract}

\section{Introdução}

Em um mundo de constante mudanças e globalizado, o conhecimento ganha uma posição cimeira face a outros recursos.

A Internet trouxe a possibilidade não só da rapidez na conectividade, mas também a possibilidade de recurso a informações nunca vivenciadas. No entanto a exposição a uma gama de informações conduz-nos à necessidade de uma reflexão de como otimizar os recursos da Web para melhoria da qualidade de vida das pessoas e comunidade.

Por outro lado, a globalização trouxe o fenómeno da competitividade e daí a necessidade de qualificação dos recursos humanos e a atualização dos conhecimentos, uma vez que as mudanças que se operam na sociedade são múltiplas e frequentes.

Os países mais vulneráveis a nível socioeconómico necessitam de empreender esforços redobrados para se inserirem na economia mundial, pelo que é incontornável a aposta nos recursos humanos.

Nesse âmbito a formação de professores de qualidade é uma das formas de assegurar a qualificação dos recursos humanos. É imprescindível que sejam criadas condições para que esta formação cumpra os seus objetivos, geralmente formulados ao nível de cada sistema educativo, mas é igualmente necessária a implementação de mecanismos de monitorização e avaliação.

Este trabalho que ora apresentamos constitui parte do trabalho de investigação que está sendo desenvolvido no âmbito do doutoramento e versa sobre as opiniões de estudantes dos cursos de Ciências da Educação e de ramo ensino.

Assim dos objetivos propostos destacamos: -Analisar os cursos do ramo ensino (formação de professores do ensino secundário) oferecidos pela Uni-CV.
Por questões de economia de espaço, limitaremos a apresentar o tratamento dos dados sem gráficos e quadros.

\section{Metodologia}

Considerando que a dimensão da população da investigação no global, abrange professores em regime integral, que lecionam no Campus do Palmarejo, nos cursos do ramo ensino, dirigentes (Presidentes de Departamentos, Coordenadores de Curso e Pró-Reitor) estudantes do primeiro e quatro anos de licenciatura dos cursos do ramo ensino, optamos por um estudo de tipo de pesquisa que nos permite uma maior rentabilização e aquisição de dados fiáveis.

No entanto embora se trata de um estudo exploratório com características descritivas, assumimos que os dados recolhidos são representativos da população e sendo assim com possibilidade de generalização de resultados.

O modelo de investigação utilizado da autoria da Fundação Chile preconiza os seguintes parâmetros: Liderança e Direção, Competências Docentes, Plano Estratégico, Sistema de Avaliação e Acompanhamento, Gestão do Processo Curricular, Administrativo e Financeiro, Acompanhamento e Monitorização, Avaliação de Resultados e Responsabilidade Social.

Por questões de economia de espaço, limitaremos a apresentar o tratamento de dados sem os gráficos e quadros.

\section{Caraterísticas dos participantes}

Constitui a população desse estudo, os estudantes do primeiro e último (quarto) ano de cursos de licenciatura em ensino e em Ciências da Educação.

Devido à impossibilidade de estudarmos todo o universo da população optamos por uma amostra representativa da população, que nos permite a compreensão exata dos fenómenos. De acordo com Fox (1981) é importante se ter em conta a representatividade da amostra e não o tamanho da amostra.

Foram auscultados $10 \%$ de estudantes do $1^{\circ}$ ano e $4^{\circ}$ ano dos cursos de Ciências da Educação e do ramo ensino.

Participaram nas respostas ao inquérito estudantes sendo $n=9$ do sexo masculino correspondendo a $45 \%$ e $\mathrm{n}=12$ estudantes do sexo feminino isto é $55 \%$.

Relativamente à idade, $45 \%$ possuem de 25 a 29 anos, $36 \%$ de 20 a 24 anos e $18 \%$ com idade superior a 30 anos.

\section{Técnicas de recolha e tratamento de dados}

Tendo em conta o objetivo da investigação que é de aprofundar os nossos conhecimentos sobre a forma como a população em estudo perceciona a qualidade e de como 
é feita a gestão dessa qualidade do ensino oferecido, recorremos à técnica de inquérito por questionário aos estudantes.

Embora conscientes das limitações que a aplicação de questionário carrega, designadamente, o preenchimento incompleto, ausência de uma reflexão cuidada (quando se trata de questionários longos), a não devolução, consideramos que as vantagens de recolha de uma gama de informações em tempo recorde, a facilidade da comparabilidade desses dados superam de longe as limitações.

Os dados recolhidos da amostra sofreram tratamento estatístico com o apoio do programa Excel. Os métodos utilizados baseiam-se na distribuição de frequência, medidas de tendência central (média aritmética).

\section{Apresentação e discussão dos resultados}

Liderança e Direção

Para 45\% dos inquiridos, o reitor não realiza encontros frequentes com estudantes, apenas 18\% concordam.

No que respeita aos encontros realizados pelo Presidente do Departamento, 68\% afirmam que não são realizados contra $5 \%$ que concordam.

Situação idêntica se verifica no que respeita a encontros realizados pelo Coordenador do Curso com os estudantes. 59\% dizem não acontecer contra 32\% que afirmam que ocorrem.

A participação nas tomadas de decisões na universidade não inclui estudantes, na opinião de 59\%. No entanto para 32\% existe participação.

A participação ao nível do departamento não é vista como uma realidade, para 50\%. Apenas 14\% afirmam a existência dessa participação.

A participação dos estudantes nas tomadas de decisões a nível do curso não acontece na opinião de 55\% contra $32 \%$.

A nível da Associação de Estudantes o cenário se inverte. 64\% afirmam que há participação estudantil contra $18 \%$.

No nosso entendimento existe um défice de comunicação e participação dos estudantes nos órgãos de gestão à exceção da Associação de Estudantes.

Segundo Chiavenatto (1994) e Teixeira (1998), a participação dos liderados é importante na motivação desses mesmos.

\section{Competências docentes}

A qualidade das aulas ministradas é percebida por mais da metade (64\%) dos inquiridos, contra $9 \%$.

No que respeita a adequação das metodologias utilizadas, verifica-se um número reduzido de opiniões. $12 \%$ acreditam que as metodologias favorecem a compreensão contra $9 \%$.

Relativamente à existência de relações interpessoais harmoniosas, entre docentes e estudantes, 64\% garantem a existência contra $9 \%$.

Os docentes tratam os estudantes com cortesia, na opinião de 55\%, contra $19 \%$ que não concordam.

Quase metade (59\%) acredita que os docentes possuem competências para a lecionação. Entretanto uma percentagem menor (19 \%) não concorda.
$50 \%$ dos estudantes se referem ao conhecimento dos critérios de avaliação das aprendizagens, contra $10 \%$.

Os estudantes consideram que os professores têm competências científicas, pedagógicas e relacionais.

Revelam conhecimento acerca dos critérios de avaliação.

A qualificação dos docentes constitui um dos parâmetros da qualidade do ensino (Gadotti, 2009).

Plano Estratégico

O plano de atividades do curso é divulgado no entender de $50 \%$. No entanto uma minoria de $23 \%$ discordam.

Em relação à participação dos estudantes na elaboração do plano de atividades do curso, uma boa parte (64\%) da população inquirida afirma que tal não ocorre.

Segundo $37 \%$ dos inquiridos, os estudantes não participam na execução do plano; apenas 18\% afirmam.

45\% não sabem da existência de um plano estratégico.

Porém 9\% discordam.

Não existe um plano estratégico. Contudo os Departamentos possuem plano de atividades no qual os estudantes não participam na sua elaboração.

Novamente verifica-se a participação nula de estudantes nos destinos da instituição.

\section{Sistema de Avaliação e Acompanhamento}

A coordenação do curso acompanha todo o processo de ensino (41\%); 28 \% discordam dessa afirmação.

Os estudantes são informados dos resultados de aprendizagem (60\%). Para $23 \%$ essa situação não acontece.

No que diz respeito ao atendimento semanal dos estudantes, 54\% afirmam, mas 32\% entendem que essa atividade é inexistente.

O processo de aprendizagem é devidamente acompanhado e aos estudantes são informados dos resultados de aprendizagem.

Entendemos ser importante o acompanhamento sistematizado dos estudantes considerando que propicia a introdução de medidas corretivas ao longo do percurso.

Gestão do Processo Curricular, Administrativo e Financeiro

Os planos de estudos são do conhecimento da maioria (72\%). Contudo 13\% opinam negativamente.

O currículo oferecido satisfaz a necessidade de formação na área concernente (73\%). 14\% não compartilham da mesma opinião.

Permite também o desenvolvimento de competências pertinentes para o mercado de trabalho (78\%); 5\% discordam.

Existe uma onda de otimismo relativamente ao ingresso no mercado de trabalho após a conclusão do curso (68\%), contra 19\% que se mostram pessimistas.

No que respeita à pertinência dos recursos bibliográficos colocados à disposição da comunidade académica, 54\% reclamam da insuficiência desses recursos, enquanto $23 \%$

afirmam que os mesmos existem em quantidade suficiente e que são pertinentes. 
As inovações introduzidas no plano de estudos do curso são pertinentes, afirmam 32\%; mas $14 \%$ discordam.

Os programas pedagógicos são disponibilizados aos estudantes no início de cada semestre (63\%). 14\% asseguram o contrário.

Relativamente a publicação dos resultados escolares no prazo estabelecido, $68 \%$ afirmam que tal atividade não se verifica, mas $18 \%$ asseguram posição contrária.

No que respeita à emissão dos certificados $63 \%$ asseguram que não são disponibilizados em tempo oportuno contra $14 \%$ que acreditam que sim.

Para 45\% dos inquiridos, a vida académica do estudante não se encontra atualizada, mas $18 \%$ afirmam.

Metade (50\%) dos estudantes mostra-se insatisfeita com os serviços prestados pelos Serviços Académicos. Porém 14\% estão satisfeitos.

$54 \%$ dos estudantes auscultados não usufruem de uma bolsa de estudos. No entanto, 41\% são bolseiros.

A seleção dos bolseiros constitui um processo transparente (32\%). 23\% não asseguram o mesmo.

A maioria (64\%) cumpre com os seus compromissos financeiros enquanto $27 \%$ não conseguem fazê-lo.

Para 64\%, o pagamento das propinas constitui um processo bem monitorizado pelos Serviços Académicos; 14\% não concordam com essa afirmação.

Aos estudantes com constrangimentos financeiros não lhes são concedidas outras oportunidades (36\%). 23\% reconhecem que estas existem.

$\mathrm{O}$ valor atribuído às propinas representa um preço justo (54\%). Contudo 32\% não concordam.

Os planos de estudos são amplamente divulgados no seio dos estudantes e se adequam à formação oferecida e às necessidades de mercado. Entretanto a disponibilização dos recursos bibliográficos é deficiente.

A carência do material bibliográfico é preocupante no sentido que limita a aprendizagem.

No que respeita à gestão administrativa, os Serviços Académicos publicam os resultados obtidos mas na emissão de documentos existe fragilidades. Metade dos estudantes se mostram insatisfeitos com o serviço prestado.

Quase metade de estudantes não possui apoios socio educativos embora deles carecem. Entretanto o processo de atribuição de bolsas é transparente. Não obstante os constrangimentos financeiros enfrentados, a maioria honra os seus compromissos.

A gestão financeira é eficiente eficaz.

Assim julgamos ser pertinente e urgente a melhoria dos Serviços Administrativos sob pena se tal não ocorrer pôr em causa a componente pedagógica.

\section{Acompanhamento e Monitorização}

O acompanhamento contínuo das aprendizagens é realizado pelos docentes (46\%). Entretanto $28 \%$ não pensam de igual forma.

Aos estudantes que revelam dificuldades de aprendizagem, os docentes propõem atividades de superação (32\%); 28\% discordam.

Para 27\%, os estudantes não recebem feedback dos resultados escolares por parte dos professores ao longo do semestre, mas $23 \%$ concordam.
55\% afirmam que ao longo do semestre vão monitorizando as respetivas aprendizagens contra 14\% de discordantes.

Ao longo do semestre, os docentes procedem à avaliação contínua e introduzem medidas de superação o que está em concordância com o que a bibliografia especializada recomenda.

\section{Avaliação dos Resultados}

$45 \%$ concordam com os resultados de aprendizagem, mas $23 \%$ discordam.

A universidade não realiza a avaliação de desempenho docente (41\%). Porém uma pequena percentagem afirma que é realizada (5\%).

$\mathrm{Na}$ avaliação de desempenho do docente não participam os estudantes (59\%).

No que respeita a realização da avaliação institucional na universidade, a maioria não tem opinião (60\%). 14\% afirmam contra igual percentagem que discorda.

O ensino oferecido é de qualidade (41\%). 14\% discordam dessa afirmação.

Os estudantes desconhecem a existência da avaliação de desempenho docente e da avaliação institucional.

Declaram concordar com a avaliação das aprendizagens.

\section{Responsabilidade Social}

A interação estudante e comunidade existe no entender de $32 \%$ dos inquiridos. Igual percentagem discorda.

Inquiridos sobre o trabalho de voluntariado, 37\% discordam que praticam. 27\% revelam a existência.

$41 \%$ discordam sobre a existência de projetos de estudantes para o apoio à comunidade e 19\% concordam.

Relativamente a intervenção na comunidade com ações de sensibilização, $27 \%$ concordam e $23 \%$ discordam.

A interface universidade e comunidade é bastante deficitária. Porém existem algumas iniciativas.

Compreendemos que essa relação seja ténue pelo fato da universidade ser bastante jovem. Não obstante, pensamos ser pertinente o fortalecimento dessa relação no sentido que os ganhos são mútuos.

\section{“Análise global”.}

A análise do quadro abaixo permite perceber que relativamente as categorias constantes no guião de inquérito, os estudantes inquiridos se posicionam da seguinte forma:

A Uni-CV possui um défice em termos de liderança e direção.

No entendimento dos mesmos os docentes possuem competências científicas e pedagógicas.

Entretanto no que respeita à existência do plano estratégico, não têm opinião.

Para os inquiridos existe um sistema de avaliação e acompanhamento eficiente e eficaz.

São da opinião que existe uma gestão curricular, mas a gestão administrativa é deficiente. Por outro lado concordam com a existência de uma gestão financeira.

No que se refere ao sistema de acompanhamento esse se revela operacional.

No que diz respeito à avaliação dos resultados, não opinam. 
Quanto à responsabilidade social da Uni-CV, os inquiridos também não têm opinião.

\section{Quadro de contingência}

\begin{tabular}{|c|c|c|c|c|c|}
\hline \multirow{2}{*}{ Categorias } & \multicolumn{5}{|c|}{ Escala } \\
\hline & 1 & 2 & 3 & 4 & 5 \\
\hline Liderança & 1,77 & 1,9 & 1,5 & 1,5 & 0,36 \\
\hline $\begin{array}{l}\text { Competências } \\
\text { docentes }\end{array}$ & 0,18 & 0,73 & 1,32 & 2,77 & 0,68 \\
\hline Plano estratégico & 0,50 & 0,82 & 1,45 & 1,00 & 0,09 \\
\hline $\begin{array}{l}\text { Sistema de } \\
\text { avaliação e } \\
\text { acompanhamento }\end{array}$ & 0,27 & 0,55 & 0,59 & 1,09 & 0,45 \\
\hline $\begin{array}{l}\text { Gestão do } \\
\text { processo } \\
\text { curricular }\end{array}$ & 0,36 & 0,95 & 1,05 & 2,95 & 1,05 \\
\hline Administrativo & 0,73 & 1,55 & 1,00 & 0,74 & 0 \\
\hline Financeiro & 1,00 & 1,00 & 1,16 & 1,79 & 1,23 \\
\hline $\begin{array}{l}\text { Acompanhamento } \\
\text { e monitorização }\end{array}$ & 0,18 & 0,77 & 1,32 & 1,41 & 0,14 \\
\hline $\begin{array}{l}\text { Avaliação dos } \\
\text { resultados }\end{array}$ & 0,64 & 0,86 & 2,09 & 0,95 & 0,09 \\
\hline $\begin{array}{l}\text { Responsabilidade } \\
\text { social }\end{array}$ & 0,27 & 1,05 & 1,27 & 1,00 & 0,05 \\
\hline
\end{tabular}

\section{Conclusões}

Os estudantes percecionam a universidade como uma instituição com uma liderança e direção deficiente.

Os docentes são competentes a nível científico, pedagógico e relacional.

A universidade não possui um instrumento de planificação a longo prazo.

Existe um sistema de avaliação e acompanhamento pedagógico funcional.

O acompanhamento e monitorização dos estudantes é desenvolvido pela coordenação de curso e pelos professores.

A avaliação das aprendizagens é justa.

No que respeita à responsabilidade social, a universidade está a dar os primeiros passos.

\section{Bibliografia}

Bonilla, J. (s/data). Gestão da Qualidade Total na Educação em

http://br.monografias.com/trabalhos908/gestaoqualidade-educacao/gestao-qualidade-educacao.shtml acessado em 02/04/2010

Cabral, J.S. (2000). Educação em Ambiente de Qualidade, in actas das Jornadas Pedagógicas. Educação XXI-Uma aposta na Qualidade. Oliveira do Douro (Vila Nova de Gaia), Centro de Formação Gaia Nascente.

Climaco,M. C. (2002). A acção imperativa", in Correio da Educação, nº 92, Porto, Ed. CriapAsa.
Davok, Deise Fries. Qualidade em educação. Avaliação (Campinas), set. 2007, vol.12, n., p.505-513. Em http://www.scielo.br/pdf/aval/v12n3/a07v12n3

Demo, P. (s/data). Qualidade da Educação-Tentativa de definir conceitos e critérios de avaliação. Avaliação Educational. Fundação Educational Carlos Chagas, Jul-Dez, 1990. Em

http://dx.doi.org/10.18222/eae00219902389

Dias, M. (2005). Como abordar...A Construção de uma Escola Mais Eficaz. AREAL Editores.

Dourado, L.F (org). et al. (2007). A qualidade na educação: conceito e definições. Brasília, INEP/MEC (Série "Textos para discussão", n²4)

Formosinho, J e ferreira, F (2009). Formação de professores.

Furtado J.C (s/d). Afinal, quem manda aqui? Poder e liderança na sala de aula

Freire, P. (1997). A pedagogia da autonomia: Saberes necessários à pratica educativa. São Paulo. Paz e Terra.

Gadotti, M. (2009). A qualidade na educação. VI Congresso de Qualidade da Educação à Distancia, em http://www.paulofreire.org/Crpf/CrpfAcervo000158

Libâneo, J et al. (2003). Educação Escolar: políticas, estrutura e organização. São Paulo: Cortez.

Morão, J e zotes, L. (2008). Qualidade na Educação ou uma Educação de Qualidade: um Olhar Contemporâneo sobre as Tentativas de Avaliação da Qualidade do Ensino Superior no Brasil. IV Congresso Nacional em Excelência na Gestão.

Mortimore, P. (1995). Democracia e Eficácia no Ensino"Entrevista de Garcia, Regina Leite, in Revista Presença Pedagógica, Setembro/Outubro.

Muñoz, M.Vera e Costa, J. (1996).” Evaluation de las escuelas eficaces" in Tejedor, F e Diéguez J. evaluation educativa y Evaluation. Institucional-Fundamentos teóricos y aplicaciones práticas Univ. de Salamanca

Souza, P.R .Um exame para os professores. In Estado de S. Paulo, 22 de Abril de 2007.

UNESCO. Los países de la America Latina y el Caribe adoptan, la Déclaration de Cochabamba. In Anais de la información Pública para América Latina em http $\backslash$ iesalc.org. 